\title{
Incidence of post myocardial infarction left ventricular thrombus formation in the era of primary percutaneous intervention and glycoprotein IIb/IIla inhibitors. A prospective observational study Arshad Rehan ${ }^{\dagger 1}$, Manpreet Kanwar ${ }^{\dagger 1}$, Howard Rosman*†1, Sujood Ahmed ${ }^{\dagger 1}$, Arshad Ali ${ }^{\dagger 2}$, Julius Gardin ${ }^{\dagger} 1$ and Gerald Cohen ${ }^{\dagger 1}$
}

Address: ${ }^{1}$ Department of Cardiology, St John Hospital and Medical Centre, Wayne State University, 22101 Moross Road, Detroit, Michigan 48230, USA and 2Department of Cardiology, Guthrie Clinic Sayre, Guthrie Square, Sayer, Pennsylvania 18840, USA

Email: Arshad Rehan - arshad.rehan@stjohn.org; Manpreet Kanwar - manpreet.kanwar@stjohn.org;

Howard Rosman* - howard.rosman@stjohn.org; Sujood Ahmed - sujood.ahmed@stjohn.org; Arshad Ali - alimd1992@aol.com; Julius Gardin - julius.gardin@stjohn.org; Gerald Cohen - gerald.cohen@stjohn.org

* Corresponding author †Equal contributors

\section{Published: 06 April 2006}

Cardiovascular Ultrasound2006, 4:20 doi:10.1/86/1476-7|20-4-20
Received: 19 February 2006

Accepted: 06 April 2006

This article is available from: http://www.cardiovascularultrasound.com/content/4/I/20

(c) 2006Rehan et al; licensee BioMed Central Ltd.

This is an Open Access article distributed under the terms of the Creative Commons Attribution License (http://creativecommons.org/licenses/by/2.0), which permits unrestricted use, distribution, and reproduction in any medium, provided the original work is properly cited.

\begin{abstract}
Background: Before the widespread use of primary percutaneous coronary intervention (PCl) and glycoprotein Ilb/llla inhibitors (GP Ilb/llla) left ventricular (LV) thrombus formation had been reported to complicate up to $20 \%$ of acute myocardial infarctions (AMI). The incidence of LV thrombus formation with these treatment modalities is not well known.
\end{abstract}

Methods: 92 consecutive patients with ST-elevation AMI treated with PCl and GP Ilb/llla inhibitors underwent 2-D echocardiograms, with and without echo contrast agent, within 24-72 hours.

Results: Only $4 / 92$ (4.3\%) had an LV thrombus, representing a significantly lower incidence than that reported in the pre- $\mathrm{PCl}$ era. Use of contrast agents did not improve detection of $\mathrm{LV}$ thrombi in our study.

Conclusion: The incidence of LV thrombus formation after acute $\mathrm{MI}$, in the current era of rapid reperfusion, is lower than what has been historically reported.

\section{Background}

A well-recognized complication of acute myocardial infarction (AMI) is the development of a left ventricular (LV) thrombus. Causes of LV thrombus include segmental dysfunction of the infarcted myocardium causing stasis, endocardial tissue inflammation providing a thrombogenic surface, and a hypercoagulable state [1-6]. There is evidence that LV thrombi usually develop within a few days after AMI [2,7-9].
Historically, the incidence of LV thrombi complicating AMI had been reported to be $20-40 \%$, and may reach $60 \%$ among patients with large anterior wall AMI [10]. Early thrombolytic therapy reduces this incidence $[5,6,11]$. However, there is little data on the incidence of LV thrombus formation after primary percutaneous coronary intervention (PCI), with concurrent use of IIb/IIIa inhibitors, for AMI. We hypothesized that with improved reperfusion using catheter-based techniques, together with the use of potent platelet glycoprotein IIb/IIIa inhib- 
Table I: Baseline demographics

\begin{tabular}{lc}
\hline & $\mathbf{n}(\%)$ (Total $\mathbf{n}=\mathbf{9 2})$ \\
\hline Mean Age in Years (Range) & $59(30-87)$ \\
Males & $57(62 \%)$ \\
History of coronary disease & $17(18 \%)$ \\
Hypertension & $47(51 \%)$ \\
Congestive Heart Failure & $2(2 \%)$ \\
Diabetes Mellitus & $22(24 \%)$ \\
Medications on admission & $19(21 \%)$ \\
- Beta-Blocker & $9(10 \%)$ \\
- ACEl & $22(24 \%)$ \\
- Aspirin & 0 \\
- Clopidogrel & $1(1 \%)$ \\
- Warfarin & $14(15 \%)$ \\
- Statins & \\
\hline
\end{tabular}

$\mathrm{n}$ : Number

$\%$ denotes percentage of each characteristic among total patients

ACEl: Angiotensin Converting Enzyme Inhibitor

itor therapy [12], the incidence of post AMI LV thrombus formation would be lower than what had been reported in the pre-PCI era. To increase the sensitivity of standard two-dimensional echocardiography (2-D echo) for detection of an LV thrombus, we used a third-generation contrast agent to outline the LV cavity structures.

\section{Methods}

Ninety-two consecutive patients presenting to our institution with ST elevation AMI and treated with PCI, rescue angioplasty after failed thrombolysis, or 'facilitated' PCI were enrolled in the study. Written informed consent was obtained from the patients prior to enrolment. Baseline demographic characteristics, pre- and post-intervention Thrombolysis in Myocardial Infarction flow grade, type of intervention, and other therapies instituted were recorded. Two-dimensional echocardiography was performed using a Vivid-7 ultrasound machine (GE Medical Systems) within three days of the PCI, by a registered sonographer, with and without an echo contrast agent (Perflutren Lipid Microspheres - Definity ${ }^{\oplus}$, Bristol-Myers Squibb Inc), with digital storage for later off-line analysis. Second harmonic imaging was used to optimise endocardial visualization. Two level-3 echocardiographers blinded to the clinical details separately reviewed the echo images in each patient. The contrast images were stored and reviewed separately from the non-contrast images. LV thrombus was defined as an echodense mass with definite margins, contiguous but distinct from the endocardium, adjacent to an area of hypo- or akinetic myocardium [1]. In cases where there was a difference of interpretation between the two readers, both readers reviewed the images together and came to a consensus. A single reader, blinded to the clinical and 2-D echo details of the patients reviewed the angiographic data.

\section{Results}

Fifty-seven men and 35 women were studied, with a mean age of 60 years (range: $30-87$ years) (Table 1 ). Forty-one patients had an inferior MI involving the right coronary artery, 37 had an anterior MI with the left anterior descending artery as the culprit vessel, 5 patients had an infarct related to the left circumflex, 4 had an acute occlusion of an obtuse marginal branch, 3 had occluded vein grafts and one each had occlusion of the ramus intermedius branch and the major diagonal branch. All patients had ST elevation on their presenting electrocardiograms. Eight patients underwent PCI for failed thrombolysis and 10 had 'facilitated' PCI after administration of half-dose thrombolytics. All but 5 patients received glycoprotein IIb/IIIa inhibitor therapy. Stents were deployed in 78 patients, whereas 14 patients had angioplasty alone. Only 1 patient failed to achieve TIMI III flow in the infarct related vessel.

Four patients, all with an anterior MI (4.3\% of the total, $10.8 \%$ of the anterior MI group), had a definite LV thrombus, both on unenhanced and enhanced imaging with perflutren lipid microspheres (Table 2). The thrombus was located in the LV apex in all 4 cases (Figure 1). All 4 were men (Table 3 ), with a mean age of 71 years (range 52 - 81 years); all demonstrated an occlusion of the proximal or mid LAD, and achieved TIMI III flow after PCI. The mean LV ejection fraction was 31\% (range 20-40\%). None of the 4 had a prior history of coronary artery disease. Three of these patients had undergone primary PCI and received IIb/IIIa therapy, whereas one patient, who did not receive GP IIb/IIIa inhibitor therapy, underwent rescue PCI after failing thrombolytic therapy. Echo contrast agent did not reveal LV thrombus in any patient where one was not seen on routine, unenhanced 2-D echocardiogram.

\section{Discussion}

Previous studies have shown that mural thrombi occur in approximately $20 \%$ of all patients who do not receive reperfusion therapy [10]. This incidence rises to $40 \%$ in case of anterior AMI and further to $60 \%$ in cases of large anterior AMI involving the LV apex10. Patients with LV thrombi have a worse overall prognosis [13], with about $10 \%$ thrombi resulting in systemic embolization [10]. Strategies to prevent this complication therefore represent an important therapeutic goal.

Although the introduction of thrombolytic therapy for treatment of AMI improved survival, its impact on the incidence of LV thrombus formation has varied. Bhatnagar, et-al showed a 3 -fold reduction in the incidence of $\mathrm{LV}$ 


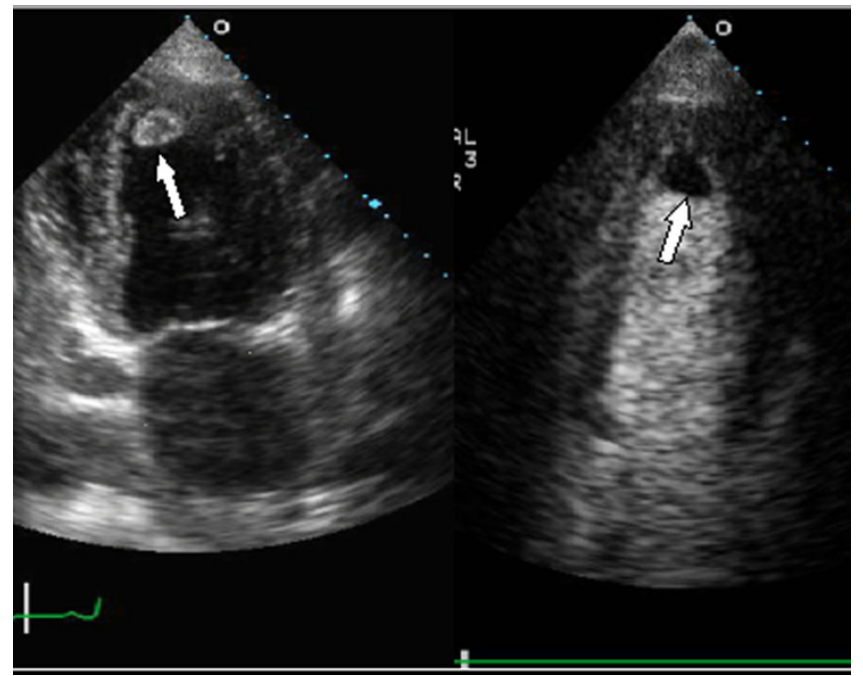

Figure I

Thrombus in left ventricular apex. Thrombus noted in left ventricular apex (white area in non-contrast enhanced image on left, black lucent area in contrast enhanced image on right)

thrombus in patients receiving early intravenous recombinant tissue plasminogen activator [5]. A sub study of the Gruppo Italiano per lo Studio della Sopravvivenza nell'infarto miocardico (GISSI-2), however, failed to show a significant reduction in the incidence of $\mathrm{LV}$ thrombus formation in AMI patients with thrombolytic agents [14]. An analysis of the subsequent GISSI-3 database by Chiarella et al, however, showed a significant reduction in the incidence of LV thrombus in patients with AMI [15]. In a meta-analysis of 6 studies, Vaitkus and Barnathan found an association between thrombolytic therapy and reduced LV thrombus formation, although it did not achieve statistical significance [11].

Catheter-based reperfusion therapy is superior to thrombolytics in promoting early myocardial recovery, with improved clinical outcomes [12]. Primary PCI, with or without stenting, has thus become the treatment of choice for patients with AMI in institutions with facilities for emergency cardiac catheterization $[16,17]$. The introduction of potent glycoprotein IIb/IIIa (GP IIb/IIIa) inhibitor agents has further improved the procedural outcomes for PCI with stenting in AMI $[12,18,19]$. In one small study, the incidence of LV thrombus formation after AMI in patients undergoing primary PCI, was reported to be as low as to $4 \%$ [20]. Porter et al, in a retrospective study of AMI patients who received either thrombolytics or primary PCI, with or without GP IIb/IIIa inhibitors, reported a $23.5 \%$ incidence of LV thrombus after anterior AMI [21]. Our study is unique in that it prospectively evaluates LV thrombus formation in AMI patients receiving both pri-
Table 2: Relationship between infarct location and thrombus formation

\begin{tabular}{ccc}
\hline Infarct Location & $\begin{array}{c}\text { Number of } \\
\text { Patients }\end{array}$ & LV Thrombus n (\%) \\
\hline Anterior & 37 & $4(10.8)$ \\
Inferior & 42 & 0 \\
Posterior-Inferior & 12 & 0 \\
Lateral & $\mathrm{I}$ & 0 \\
Total & $\mathbf{9 2}$ & $\mathbf{4 ( 4 . 3 )}$ \\
\hline
\end{tabular}

$\mathrm{n}$ : Number

$\mathrm{LV}=$ Left ventricular

$\%$ represents percentage of a characteristic within each category

mary PCI and GP IIb/IIIa inhibitors. It confirms a significant reduction in this complication that parallels improvement in other post-MI outcomes as a result of better contemporary therapy. We also used echo contrast agent in all patients and found no additive value in detection of post MI LV thrombi.

It is important to review the role of echocardiography in the diagnosis of LV thrombi. The sensitivity and specificity of 2-D echo in the diagnosis of LV thrombi has been established, even with first and second-generation echo equipment, to be in excess of $92 \%$ and $86-88 \%$, respectiviely1. With modern, improved imaging equipment, the sensitivity is expected to be even higher. Nonetheless 2-D echo has certain limitations. First, a small thrombus (e.g., < 5-6 mm) may not be accurately detected [22]. Second, differences in acoustic impedance between endocardium and freshly formed thrombus may not be sufficient to allow clear definition of the thrombus. Third, various other anatomic structures, such as false tendons or trabeculae, may confound the diagnosis [1]

The use of contrast agents has been reported to add to the sensitivity of non-contrast 2-D echo [23] in the diagnosis of LV thrombi, although in our study, contrast agents did not detect any additional thrombi. The use of contrast adds US $\$ 110$ to the cost of each study and involves approximately 5 minutes of additional imaging time. Perhaps it would be reasonable to reserve contrast agents for patients with sub-optimal 2D imaging which precludes adequate visualization of the endocardium. Given the small number of patients with thrombi in our study the additive value of contrast should be interpreted with caution.

\section{Conclusion}

In conclusion, the incidence of early LV thrombus formation is lower (4\% for all MI's, 11\% for anterior MI's) in this era of primary PCI, coupled with the use of potent antithrombotic and anti-platelet agents, compared to historical data in the pre-PCI era (up to $20 \%$ for all MI's, 
Table 3: Features of patients with left ventricular thrombi

\begin{tabular}{|c|c|c|c|c|}
\hline & Patient I & Patient 2 & Patient 3 & Patient 4 \\
\hline Age (years) & 68 & 81 & 52 & 81 \\
\hline Sex & Male & Male & Male & Male \\
\hline IRA & Prox LAD & Prox LAD & Mid LAD & Prox LAD \\
\hline Lytics & No & No & No & Yes (failed) \\
\hline $\mathrm{PCl}$ & Stent & Stent & Stent & Stent \\
\hline Ilb/IIla & Yes & Yes & Yes & No \\
\hline $\mathrm{EF}$ & $23 \%$ & $32 \%$ & $35 \%$ & $30 \%$ \\
\hline
\end{tabular}

IRA $=$ Infarct related artery

LAD $=$ Left Anterior Descending artery, Prox $=$ Proximal

$\mathrm{PCl}=$ Percutaneous Intervention

$\mathrm{EF}=$ Ejection Fraction

$40 \%$ for anterior MI's). Routine use of echo contrast agents did not improve detection of LV thrombi in our study.

\section{Competing interests}

The author(s) declare that they have no competing interests.

\section{Authors' contributions}

AR conceived the study and drafted the manuscript

MK recruited patients and assisted in data collection

HR analysed the echocardiographic images and made important revisions to the manuscript

SA participated in acquisition and analysis of the data.

AA participated in design and coordination of the study and interpreted the angiograms

JG made important intellectual contributions to the manuscript

GC worked on data analysis and interpretation of echocardiograms, and made important contributions to the manuscript

\section{Acknowledgements}

Renee Bess RDCS, RVT, FASE.

St John Hospital and Medical Centre, Detroit, Michigan, USA.

\section{References}

I. Stratton JR, Lighty GW, Pearlman AS, Ritchie JL: Detection of left ventricular thrombus by two-dimensional echocardiography: sensitivity, specificity and causes of uncertainty. Circulation 1982, 66: $156-166$

2. Visser CA, Kan G, David GK, Lie KI, Durrer D: Two-dimensional echocardiography in the diagnosis of left ventricular thrombus. A prospective study of 67 patients with anatomic validation. Chest 1983, 83:228-232.
3. Domenicucci S, Bellotti P, Chiarella F, G Lupi, Vecchio C: Spontaneous morphologic changes in left ventricular thrombi: a prospective two dimensional echocardiographic study. Circulation 1987, 75:737-743.

4. Lamas GA, Vaughan DE, Pfeiffer MA: Left ventricular thrombus formation after first anterior wall acute myocardial infarction. Am J Cardiol 1986, 57: I244- 247.

5. Bhatnagar SK, Al-Yusuf AR: Effects of intravenous recombinant tissue-type plasminogen activator therapy on the incidence and associations of left ventricular thrombus in patients with a first acute $\mathbf{Q}$ wave anterior myocardial infarction. Am Heart J 199|, I22:125I-1256.

6. Pizzetti G, Belotti G, Margonato A, Carlino M, Gerosa S, Carandete $O$, Chierchia SL: Thrombolytic therapy reduces the incidence of left ventricular thrombus formation in acute anterior myocardial infarction. Relationship to vessel patency and infarct size. Eur Heart J 1996, 17:42 I-428.

7. Weinreich DJ, Burke JF, Pauletto FJ: Left ventricular mural thrombi complicating acute myocardial infarction. Longterm follow-up with serial echocardiography. Ann Intern Med 1984, 100:789-794.

8. Davis MJ, Ireland MA: Effect of early anticoagulation on the frequency of left ventricular thrombi after anterior wall acute myocardial infarction. Am J Cardiol 1986, 57:1244-1247.

9. Asinger RW, Mikell FL, Elsperger J, Hodges M: Incidence of leftventricular thrombosis after acute transmural myocardial infarction. Serial evaluation by two-dimensional echocardiography. N Engl J Med I98I, 305:297-302.

10. Keeley EC, Hillis LD: Left ventricular mural thrombus after acute myocardial infarction. Clin Cardiol 1996, 19(2):83-86.

II. Vaitkus PT, Barnathan ES: Embolic potential, prevention and management of mural thrombus complicating anterior myocardial infarction: a meta-analysis. J Am Coll Cardiol 1993, 22:1004-1009.

12. Schomig A, Kastrati A, Dirschinger J, Mehilli J, Schricke U, Pache J, Martinoff S, Neumann FJ, Schwaiger M: Coronary stenting plus platelet glycoprotein IIb/IIla blockade compared with tissue plasminogen activator in acute myocardial infarction. $N$ Engl J Med 2000, 343:385-39l.

13. Held AC, Cole PL, Lipton B, Gore JM, Antman EM, Hockman JS, Corrao J, Goldberg RJ, Alpert JS: Rupture of the interventricular septum complicating acute myocardial infarction: A multicenter analysis of clinical findings and outcome. Am Heart J 1988, I 16:1330-1336.

14. Vecchio C, Chiarella F, Lupi G, Bellotti P, Domenicucci S: Left ventricular thrombus in anterior acute myocardial infarction after thrombolysis. A GISSI-2 connected study. Circulation 1991, 84:512-519.

15. Chiarella F, Santoro E, Domenicucci S, Maggioni A, Vecchio C: Predischarge two-dimensional echocardiographic evaluation of left ventricular thrombosis after acute myocardial infarction in the GISSI-3 study. Am J Cardiol 1998, 81:822-827.

16. Weaver WD, Simes RJ, Betriu A, Grines CL, Zijlstra F, Garcia E, Grinfeld L, Gibbons RJ, Ribeiro EE, DeWood MA, Ribichini F: Comparison of primary coronary angioplasty and intravenous 
thrombolytic therapy for acute myocardial infarction: a quantitative review. JAMA 1997, 278:2093-2098.

17. Yusuf S, Pogue J: Primary angioplasty compared with thrombolytic therapy for acute myocardial infarction. JAMA 1997, 278:2II0-2III.

18. Gold HK, Garabedian HD, Dinsmore RE, Guerrero LJ, Cigarroa JE, Palacios IF, Leinbach RC: Restoration of coronary flow in myocardial infarction by intravenous chimeric 7E3 antibody without exogenous plasminogen activators: Observations in animals and humans. Circulation 1997, 95:1755-1759.

19. Lefkovits J, Ivanhoe RJ, Califf RM, Bergelson BA, Anderson KM, Stoner GL, Weisman HF, Topol EJ, The Group EPIC Investigators: Effects of platelet glycoprotein IIb/IIla receptor blockade by a chimeric monoclonal antibody (abciximab) on acute and six-month outcomes after percutaneous transluminal coronary angioplasty for acute myocardial infarction. EPIC investigators. Am J Cardiol 1996, 77:1045-105I.

20. Kalra A, Jang IK: Prevalence of early left ventricular thrombus after primary coronary intervention for acute myocardial infarction. J Thromb Thrombolysis 2000, 10(2): I33-6.

21. Porter A, Kandalker H, lakobishvili Z, Sagie A, Imbar S, Battler A, Hasdai $D$ : Left ventricular mural thrombus after acute myocardial infarction in the era of aggressive reperfusion therapy still a frequent complication. Coronary Artery Disease 2005, 16:275-279.

22. Pechacek LW, Lazar AV, Sonnemaker RE, Edelman SK, De Castro CM, Hall RJ: Comparison of two-dimensional echocardiography, radionuclide ventriculography and cineangiography in detecting surgically documented left ventricular thrombi. Tex Heart Inst J 1984, I I: I I8- 127.

23. Sieswerda GT, Kamp O, Visser CA: Myocardial contrast echocardiography: Clinical benefit and practical issues. Echocardiography 2000, 17:S25-S36.

\section{Publish with Bio Med Central and every scientist can read your work free of charge}

"BioMed Central will be the most significant development for disseminating the results of biomedical research in our lifetime. "

Sir Paul Nurse, Cancer Research UK

Your research papers will be:

- available free of charge to the entire biomedical community

- peer reviewed and published immediately upon acceptance

- cited in PubMed and archived on PubMed Central

- yours - you keep the copyright 